\title{
A matemática na revista técnica Igreja Luterana
}

The mathematics in the Lutheran Church technical magazine

Malcus Cassiano Kuhn ${ }^{1}$

\section{Resumo}

O artigo é recorte de uma pesquisa sobre a Matemática nas escolas paroquiais luteranas gaúchas do século XX e analisa as edições da revista técnica Igreja Luterana, com ênfase para o discurso matemático veiculado na mesma. A revista foi editada para pastores e professores paroquiais pela Igreja Evangélica Luterana do Brasil, por meio da Casa Publicadora Concórdia de Porto Alegre, no período de 1940 a 1954. Com abordagem qualitativa e análise de fontes documentais, a investigação possui aporte metodológico na pesquisa histórica e no conceito de cultura escolar, para análise das 95 edições da revista técnica. Era desejo dos editores da revista que os professores das escolas paroquiais estivessem aptos para darem aos alunos uma instrução e educação verdadeiramente cristãs, por isso, a abordagem de temáticas teológicas e pedagógicas em suas edições. Os editores propunham artigos voltados ao desenvolvimento de habilidades para o cálculo escrito e mental, com foco nas primeiras construções numéricas pelo método de ensino intuitivo e na operação de divisão com frações.

1 Doutor em Ensino de Ciências e Matemática pela Universidade Luterana do Brasil em ULBRA. Estágio Pós-doutoral no Programa de Pós-Graduação em Ensino de Ciências e Matemática - PPGECIM, na Universidade Luterana do Brasil - ULBRA. Líder do Grupo de Pesquisa Estratégias de Ensino para Educação Básica e Profissional. Membro do Grupo de Pesquisas sobre Formação de Professores de Matemática - GPFPMat.Professor do Ensino Básico, Técnico e Tecnológico no Instituto Federal de Educação, Ciência e Tecnologia Sulrio-grandense - IFSul Câmpus Lajeado. Chefe do Departamento de Ensino, Pesquisa e Extensão Professor do Instituto Federal de Educação, Ciência e Tecnologia Sul-riograndense - IFSul Câmpus Lajeado. Coordenador do Curso de Pós-Graduação Lato Sensu Especialização em Educação e Saberes para os Anos Iniciais do Ensino Fundamental no IFSul Câmpus Lajeado. E-mail: malcusck@yahoo.com.br.

Interfaces da Educ., Paranaíba, v.10, n.28, p.101 à 124, 2019

ISSN 2177-7691

Recebido em agosto de 2019 e aprovado em setembro de 2019 
Palavras-chave: História da Educação Matemática. Escola Paroquial Luterana Gaúcha. Revista Técnica Luterana.

\section{Abstract}

The article it's a clipping of a research about Mathematics in the Lutheran parochial schools of the $20^{\text {th }}$ century and analyzes the editions of the Lutheran Church technical magazine, with emphasis on the mathematical discourse in it. The magazine was edited for pastors and parish teachers by the Evangelical Lutheran Church of Brazil, through Concordia Publishing House of Porto Alegre, from 1940 to 1954 . With a qualitative approach and analysis of documentary sources, the research has methodological support in historical research and in the concept of school culture, to analyze the 95 editions of the technical magazine. It was the desire of the editors of the magazine that the teachers of the parochial schools were able to give the students a truly Christian education and education, therefore, the approach of theological and pedagogical themes in your editions. The editors proposed articles aimed at the development of skills for the written and mental calculation, focusing on the first numeric constructions by the intuitive method of teaching and the operation of division with fractions.

Keywords: History of Mathematics Education. Gaucho Lutheran Parochial School. Lutheran Technical Magazine.

\section{Introdução}

O tema desta investigação se insere na História da Educação Matemática no Rio Grande do Sul - RS, no âmbito das Escolas Evangélicas Luteranas do Brasil. Trata-se de um estudo que contempla os imigrantes alemães e seus descendentes no estado gaúcho e tem como questão norteadora a Matemática praticada nas escolas paroquiais luteranas gaúchas do século XX. 
Este artigo tem por objetivo discutir a Matemática presente na revista técnica Igreja Luterana, com ênfase para o discurso matemático veiculado no periódico, por meio dos textos, imagens e enunciados, suas intencionalidades e abordagens. É um recorte de tese, complementado por pesquisas realizadas durante o estágio Pós-doutoral em um Programa de Pós-Graduação.

A revista técnica Igreja Luterana foi produzida pela Igreja Evangélica Luterana do Brasil - IELB - para pastores e professores luteranos e publicada pela Casa Publicadora Concórdia ${ }^{2}$, de Porto Alegre. Teve sua $1^{\text {a }}$ edição publicada em janeiro de 1940. Com publicações mensais, bimestrais, trimestrais ou quadrimestrais, a revista técnica teve 95 edições, totalizando 2850 páginas. Foi editada até abril/junho de 1954 e, posteriormente, a revista Igreja Luterana passou a ser somente teológica.

Para investigar a revista técnica Igreja Luterana se realizaram visitas ao Instituto Histórico da IELB, localizado em Porto Alegre/RS, onde se encontram todas as edições da mesma. Ao pesquisar minuciosamente cada edição, compilaram-se os excertos relacionados à Matemática para posterior análise à luz do referencial teórico-metodológico da pesquisa histórica e do conceito de cultura escolar.

No estudo da revista Igreja Luterana, além do referencial teóricometodológico, apresentam-se uma breve caracterização das escolas paroquiais luteranas gaúchas do século passado e uma discussão dos conhecimentos matemáticos abordados na revista técnica.

\section{O aporte teórico-metodológico da investigação}

Como a temática investigada se insere na História da Educação Matemática no RS, busca-se na pesquisa histórica e no conceito de cultura escolar, o suporte para discussão. De acordo com Prost (2008), os fatos

\footnotetext{
2 Fundada em 1923, atuava na edição de livros e periódicos relacionados à literatura religiosa e escolar da IELB. Foi a primeira e a única editora da IELB, existente até os dias atuais. Antes de sua fundação, os livros e os periódicos eram impressos pela Concordia Publishing House, nos Estados Unidos, e enviados ao Brasil.
} 
históricos são constituídos a partir de traços, de rastros deixados no presente pelo passado. Assim, o trabalho do historiador consiste em efetuar um trabalho sobre esses traços para construir os fatos. Desse modo, um fato não é outra coisa que o resultado de uma elaboração, de um raciocínio, a partir das marcas do passado. $\mathrm{O}$ autor considera o trajeto da produção histórica como sendo um interesse de pesquisa, a formulação de questões históricas legítimas, um trabalho com os documentos, como as edições da revista técnica Igreja Luterana, e a construção de um discurso que seja aceito pela comunidade.

Certeau (1982) define o fazer história, no sentido de pensar a história como uma produção. Para o autor, a história, como uma produção escrita, tem a tripla tarefa de convocar o passado que já não está em um discurso presente, mostrar as competências do historiador (dono das fontes) e convencer o leitor. Desta forma, a prática histórica é prática científica enquanto a mesma inclui a construção de objetos de pesquisa, o uso de uma operação específica de trabalho e um processo de validação dos resultados obtidos, por uma comunidade.

O trabalho do historiador, de acordo com Certeau (1982), não se limita a produzir documentos, textos em uma nova linguagem. Isso ocorre porque no seu fazer pesquisa há um diálogo constante do presente com o passado, e o produto desse diálogo consiste na transformação de objetos naturais em cultura. Julia (2001) define a cultura escolar como:

Um conjunto de normas que estabelecem conhecimentos a ensinar e condutas a inculcar, e um conjunto de práticas que permitem a transmissão desses conhecimentos e a incorporação desses comportamentos; normas e práticas coordenadas a finalidades que podem variar segundo às épocas. (JULIA, 2001, p.10).

Então, o estudo da cultura escolar instiga a busca pelas normas e finalidades que regem a escola, a avaliação do papel desempenhado pelo professor e a análise dos conteúdos ensinados e das práticas escolares. Chervel (1990) considera importante o estudo da cultura escolar para a compreensão dos elementos que participam da 
A matemática na revista técnica Igreja Luterana...

produção/elaboração/constituição dos saberes escolares e, em particular, da matemática escolar e sua história.

Conforme Valente (2007), há uma infinidade de materiais que junto com os livros didáticos podem permitir compor um quadro da Educação Matemática de outros tempos. Para o autor, pensar os saberes escolares como elementos da cultura escolar, realizar o estudo histórico da matemática escolar, exige que se devam considerar os produtos dessa cultura do ensino de Matemática, que deixaram traços que permitem o seu estudo, como a revista técnica Igreja Luterana, principal fonte documental desta investigação. Antes, porém, é preciso fazer uma breve abordagem sobre as escolas paroquiais luteranas gaúchas do século XX.

\section{As escolas paroquiais luteranas gaúchas do Século $\mathbf{X X}$}

No Brasil, os princípios cristãos de Lutero, se fizeram presentes, a partir de 1824, com a vinda das ideias luteranas através dos primeiros imigrantes alemães. Lutero traçou princípios gerais sobre a educação, os quais se fundamentaram na Bíblia. "A premissa fundamental é de que a Bíblia ensina que Deus criou o universo e mantém, governa e sustenta toda a criação, sendo o homem a obra máxima da criação". (LEMKE, 2001, p. 34).

Nesta perspectiva luterana, o Sinodo Evangélico Luterano Alemão de Missouri ${ }^{3}$, atualmente IELB, começou sua missão nas colônias alemãs do RS, em 1900, fundando congregações religiosas e escolas paroquiais. Para o Sínodo de Missouri era necessário consolidar um campo religioso e fortalecêlo investindo na escola, influenciando o campo familiar dos seus possiveis fiéis. Por isso, os missourianos não somente cuidaram da formação de pastores como também de professores que atuassem de acordo com a filosofia educacional missouriana para que as escolas paroquiais atingissem seus objetivos como agência missionária e de educação geral.

\footnotetext{
3 Em 1847, um grupo de imigrantes luteranos alemães da Saxônia fundou no estado de Missouri (Estados Unidos), o Sínodo Evangélico Luterano Alemão de Missouri, Ohio e Outros Estados, atualmente Igreja Luterana - Sínodo de Missouri.
} 
Conforme Kuhn e Bayer (2017b), as escolas paroquiais luteranas gaúchas estavam inseridas num projeto missionário e comunitário que buscava ensinar a língua materna, a Matemática, valores culturais, sociais e, principalmente, religiosos. Tais escolas:

\begin{abstract}
Tinham uma responsabilidade para com a comunidade no sentido de, junto e com ela, promover o crescimento e o desenvolvimento pessoal de todos que a compunham, focando a cidadania. Se a escola formasse o ser humano com postura ética e moral exemplar, este poderia promover transformações sólidas em seu contexto social e seria um verdadeiro colaborador na seara de Deus e para o governo do mundo. (KUHN; BAYER, 2017b, p. 132).
\end{abstract}

As escolas paroquiais luteranas gaúchas, geralmente, eram constituídas por classes multisseriadas, mantidas pela comunidade escolar/paroquial e subvencionadas pelo Sínodo de Missouri para pagamento do salário do professor/pastor. Como havia poucos materiais didáticos nestas escolas, o ensino acontecia na base da recitação e da memorização. Os professores paroquiais eram formados pelo Seminário Concórdia ${ }^{4}$, de acordo com os princípios morais e religiosos da Igreja Luterana. A prática pedagógica deveria levar em consideração a realidade dos alunos, para que, futuramente, os mesmos se engajassem de forma ativa nas estruturas comunitárias. (KUHN; BAYER, 2017b).

Os egressos das escolas paroquiais luteranas gaúchas tinham maior conhecimento da Bíblia e uma formação consistente de crenças e valores cristãos tradicionais que enfatizavam a importância do relacionamento com Deus e com outras pessoas. Tinha-se a preocupação pedagógica para que a espiritualidade fosse vivida no dia a dia e não se reduzisse a ritos religiosos. (KUHN; BAYER, 2017b).

O Sinodo de Missouri também direcionava sua atenção para os materiais didáticos usados nas escolas paroquiais, pois este material era escasso e a dificuldade era grande em manter um ensino planificado e organizado. De acordo com Weiduschadt (2007, p. 41), "os livros usados nas escolas paroquiais e utilizados pelos alunos foram produzidos pelas

\footnotetext{
${ }^{4}$ Instituto pedagógico-teológico que atuou na formação de pastores e de professores paroquiais para IELB no RS.
}

Interfaces da Educ., Paranaỉba, v.10, n.28, p.101 à 124, 2019

ISSN 2177-7691 
instituições religiosas com objetivo de formar e moldar as condutas e as práticas ao fazer a escolarização das comunidades”. Assim, por meio dos livros didáticos e dos periódicos, como a revista técnica Igreja Luterana que é abordada na seção seguinte, as escolas paroquiais luteranas gaúchas conseguiram desenvolver uma educação integral cristã em todas as disciplinas. Nessas escolas, conforme Lemke (2001, p. 80), “o ensino da palavra de Deus, através da Bíblia, ficava em primeiro lugar, e as demais disciplinas não eram menosprezadas, mas complementavam a educação para servir no mundo".

De acordo com estudos realizados por Kuhn e Bayer (2017a), nas escolas paroquiais luteranas gaúchas do século passado, no ensino da Matemática se priorizavam os números naturais, os sistemas de medidas, as frações e os números decimais, complementando-se com a matemática comercial e financeira e a geometria. O ensino desta disciplina deveria acontecer de forma prática e articulada com as necessidades dos futuros agricultores, observando-se a doutrina luterana.

Conforme Schubring (2003), nos primeiros períodos de colonização, para o ensino da Matemática foram usados livros trazidos da Alemanha ou recebidos como doações. Os livros que passaram a ser produzidos no sul do Brasil, no final do século XIX, seguiram as tendências da metodologia da Matemática na Alemanha, porém, adapatando-se à realidade dos colonos no Brasil:

A editora Rotermund conseguiu obter, por meio de seus manuais de aritmética, um posição dominante no período entre as guerras, mesmo independente dos confins confessionais. (...) Após a Primeira Guerra Mundial, particularmente a série de livros Praktische Rechenschule, por Otto Büchler, publicada pela editora Rotermund em grande número de edições impressas, dominava nas escolas teuto-brasileiras. A mesma editora publicou, a partir de 1931, um novo manual de aritmética, Mein Rechenbuch, por W. Nast e L. Tochtrop, que adaptaram as novas tendências da metodologia e da pedagogia da Alemanha. A pressão da nacionalização, também na editora Rotermund, é ilustrada pelo fato de que ela se viu obrigada, nos anos 1920, a publicar uma tradução do Rechenbuch por Büchler, em Português. (SCHUBRING, 2003, p. 47). 
Os primeiros trinta anos de existência das escolas paroquiais luteranas no estado gaúcho foram marcados pela carência de materiais didáticos e pela progressiva adoção dos quatro manuais de Büchler, tanto em alemão, quanto em português, para as aulas de Matemática. Na revista Unsere Schule 5 (ago. 1933, p. 6, tradução nossa), afirma-se que "os livros de aritmética de Büchler (editora Rotermund) são usados na maioria das escolas luteranas e que a mesma editora lançou recentemente um novo manual: meu livro de contas, por W. Nast e L. Tochtrop". Porém, na mesma edição, este manual é analisado criticamente, apontando-se a necessidade de uma edição moralmente e educacionalmente correta, com uso de princípios pedagógicos modernos e adaptada às condições nacionais, pois o processo de nacionalização do ensino ${ }^{6}$ estava em curso no país.

Por isso, o Sínodo de Missouri começou a produzir seus próprios livros de aritmética na década de 1930. A Casa Publicadora Concórdia de Porto Alegre editou e publicou o material didático específico para as escolas paroquiais luteranas. "O Sínodo decidiu que será editado um trabalho completo de aritmética. Os professores Frederico Strelow, Albert Brückmann e Max Öhlwein foram contratados para realizar o trabalho" (UNSERE SCHULE, mar./abr. 1934, p. 14, tradução nossa). Para as aulas de Matemática, foram publicadas duas séries: a série Ordem e Progresso, lançada na década de 1930, pela divulgação feita na revista Unsere Schule, e a série Concórdia, lançada na década de 1940, conforme os exemplares encontrados no Instituto Histórico da IELB em Porto Alegre. De acordo com Lemke (2001, p. 79), "a série Ordem e Progresso é uma coleção constituída por livros de leitura, história bíblica e matemática em que os próprios textos de alfabetização e cálculo trazem ensinamentos bíblicos e contém temas de cunho moral e cristão".

\footnotetext{
${ }^{5}$ Nossa Escola.

6 Uma série de decretos dos governos federal e estadual, emitidos no final da década de 1930, disciplinaram a licença de professores e o material didático a ser usado nas escolas, tornaram o idioma nacional obrigatório (português) para a instrução e prescreveram a formação cívica brasileira.
} 
A matemática na revista técnica Igreja Luterana...

A Casa Publicadora Concórdia também atuou na edição e publicação de periódicos relacionados à literatura religiosa e escolar da IELB. Publicou periódicos específicos para as crianças, jovens e adultos. Atualmente, os periódicos produzidos possuem caráter teológico, predominantemente. Além de educarem e doutrinarem pela palavra de Deus, os periódicos editados pela Igreja Luterana se direcionavam para os pastores da IELB, os professores paroquiais e as crianças luteranas, trazendo artigos com orientações teológicas e didáticas e informações sobre conteúdos formais.

\section{A revista técnica Igreja Luterana}

Devido ao processo de nacionalização do ensino, a partir de 1940, o periódico luterano Wacht und Weide in Kirche und Schule ${ }^{7}$ (Guardando e Apascentando na Igreja e na Escola), começou a ser editado em português, com a denominação de Igreja Luterana. A revista técnica Igreja Luterana começou a circular em janeiro de 1940, com predominância de textos escritos em português. A revista possuía caráter técnico (teológico/pedagógico) para pastores e professores luteranos, até a edição de julho/agosto de 1954, quando passou a ser somente teológica. Era desejo dos editores da revista que os professores das escolas paroquiais estivessem aptos para darem aos alunos uma instrução e educação verdadeiramente cristãs, por isso, a abordagem de temáticas teológicas e pedagógicas em suas edições.

A $1^{\mathrm{a}}$ edição da revista técnica Igreja Luterana teve Guilherme Goerl ${ }^{8}$ como diretor. A partir da $2^{a}$ edição, foi dirigida pelo pastor Carlos Henrique Warth ${ }^{9}$. A edição de setembro/outubro de 1954 foi a última dirigida pelo

\footnotetext{
${ }^{7} \mathrm{O}$ periódico técnico Wacht und Weide in Kirche und Schule era redigido em alemão e foi editado no período de março/abril de 1936 até o final de 1939, em Porto Alegre. Dirigido aos pastores da IELB e aos professores das escolas paroquiais, o periódico teve 17 edições, apresentando textos bíblicos, notícias e artigos pedagógicos relacionados com diferentes áreas do conhecimento.

${ }^{8}$ Guilherme Goerl foi diretor da Casa Publicadora Concórdia, de Porto Alegre, por 40 anos.

9 O pastor brasileiro Carlos Henrique Warth (1902 - 1976) foi diretor dos periódicos, Wacht und Weide in Kirche und Schule, Igreja Luterana e O Pequeno Luterano, e redator dos periódicos, Jovem Luterano e Luther-Kalender. Além de cronista e estatístico da Igreja, ainda ocupou cargos administrativos na IELB.
}

Interfaces da Educ., Paranaỉba, v.10, n.28, p.101 à 124, 2019

ISSN 2177-7691 
pastor Warth. As edições técnicas da revista Igreja Luterana foram redigidas, principalmente, pelos professores Paul William Schelp ${ }^{10}$ - no período de janeiro de 1940 até abril/junho de 1954 - e Otto Adolpho Goerl ${ }^{11}$ - no período de fevereiro de 1943 a abril/junho de 1954. A Figura 1 traz um excerto da $1^{\mathrm{a}}$ página da $2^{\mathrm{a}}$ edição da revista, mostrando informações de identificação.

Figura 1 - Fragmento com identificação da $2^{a}$ edição da revista Igreja Luterana

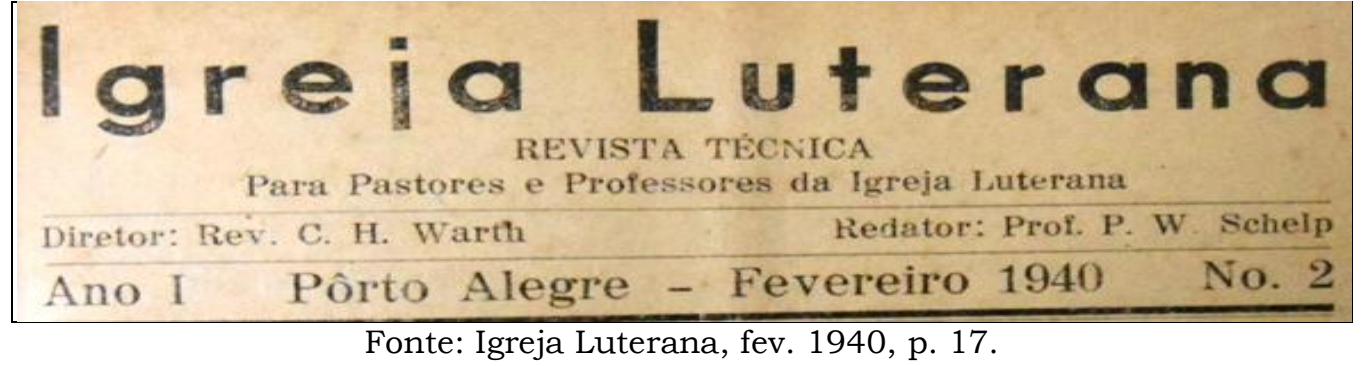

Além do título da revista, Igreja Luterana, na sequência aparece: Revista Técnica para pastores e professores da Igreja Luterana, o nome do diretor e redator da revista, ano, local, data e número de edição. A estrutura de identificação, apresentada na Figura 1, é mantida nas demais edições, havendo o acréscimo do nome do professor Goerl como redator, na edição de fevereiro de 1943, e a alteração para revista teológica, na edição de julho/agosto de 1954. No Quadro 1, apresentam-se informações gerais sobre as edições técnicas da revista Igreja Luterana.

Quadro 1 - As edições técnicas da revista Igreja Luterana

\begin{tabular}{|c|c|c|}
\hline Ano & Edições & $\begin{array}{c}\text { Total de } \\
\text { páginas }\end{array}$ \\
\hline $1-1940$ & 8 edições mensais e 2 edições bimestrais & 190 \\
\hline $2-1941$ & 6 edições bimestrais & 160 \\
\hline
\end{tabular}

10 O norte americano Paul William Schelp (1895 - 1972), formou-se pastor em 1919, vindo ao Brasil para atuar como professor de Teologia no Seminário Concórdia, de 1920 a 1969. Atuou em cargos administrativos da IELB, foi redator dos periódicos Kirchenblatt, Unsere Schule, Wacht und Weide in Kirche und Schule e Igreja Luterana, além de autor de artigos e livros relacionados à prática religiosa luterana.

11 O gaúcho Otto Adolpho Goerl (1905-1998) se formou no Seminário Concórdia, em 1925, e foi ordenado pastor em 1926. Além de pastor, foi professor paroquial e, posteriormente, professor e diretor do Seminário Concórdia. Autor de livros para o ensino da aritmética e da leitura nas escolas paroquiais luteranas. Também foi redator da revista teológica e pedagógica Igreja Luterana. 
A matemática na revista técnica Igreja Luterana...

\begin{tabular}{|c|c|c|c|}
\hline $3-1942$ & \multicolumn{2}{|c|}{$\begin{array}{c}6 \text { edições mensais e } 2 \text { edições } \\
\text { bimestrais }^{12}\end{array}$} & 172 \\
\hline $4-1943$ & \multicolumn{2}{|c|}{12 edições mensais } & 192 \\
\hline $5-1944$ & \multicolumn{2}{|c|}{6 edições mensais e 3 edições bimestrais } & 184 \\
\hline $6-1945$ & \multicolumn{2}{|c|}{5 edições bimestrais ${ }^{13}$} & 144 \\
\hline $7-1946$ & \multicolumn{2}{|c|}{2 edições mensais e 5 edições bimestrais } & 168 \\
\hline $8-1947$ & \multicolumn{2}{|c|}{$\begin{array}{c}2 \text { edições mensais, } 3 \text { edições bimestrais e } \\
1 \text { edição quadrimestral }\end{array}$} & 168 \\
\hline $9-1948$ & \multicolumn{2}{|c|}{$\begin{array}{c}2 \text { edições bimestrais e } 2 \text { edições } \\
\text { quadrimestrais }\end{array}$} & 132 \\
\hline $10-1949$ & \multicolumn{2}{|c|}{6 edições bimestrais } & 264 \\
\hline $11-1950$ & \multicolumn{2}{|c|}{6 edições bimestrais } & 240 \\
\hline $12-1951$ & \multicolumn{2}{|c|}{$\begin{array}{c}3 \text { edições bimestrais e } 2 \text { edições } \\
\text { trimestrais }\end{array}$} & 232 \\
\hline $13-1952$ & \multicolumn{2}{|c|}{$\begin{array}{c}3 \text { edições bimestrais e } 2 \text { edições } \\
\text { trimestrais }\end{array}$} & 244 \\
\hline $14-1953$ & \multicolumn{2}{|c|}{4 edições trimestrais } & 244 \\
\hline $15-1954$ & \multicolumn{2}{|c|}{2 edições trimestrais } & 116 \\
\hline Total & $\begin{array}{c}36 \text { edições mensais } \\
46 \text { edições bimestrais } \\
10 \text { edições trimestrais } \\
3 \text { edições } \\
\text { quadrimestrais }\end{array}$ & 95 edições & 2850 \\
\hline
\end{tabular}

Fonte: Igreja Luterana, 1940-1954.

O Quadro 1 permite afirmar que a revista técnica Igreja Luterana foi editada 95 vezes em seus quase 15 anos de circulação, sendo 36 edições mensais, 46 bimestrais, 10 edições trimestrais e 3 edições quadrimestrais. Portanto, geralmente, a revista era mensal ou bimestral. Nos primeiros 9 anos de edição, o número total de páginas não ultrapassou 190 em cada ano. A partir do $10^{\circ}$ ano de edição foram mais de 230 páginas por ano. Assim, a revista Igreja Luterana totalizou 2850 páginas em suas edições técnicas. A última edição técnica da revista foi publicada em abril/junho de 1954.

${ }^{12}$ A edição referente aos meses de janeiro/fevereiro de 1942 não existe, conforme informações encontradas na revista técnica Igreja Luterana.

${ }^{13}$ Não se obteve informações sobre a existência da edição referente aos meses de novembro/dezembro de 1945. 
Nas edições técnicas da revista Igreja Luterana, encontram-se textos religiosos - geralmente histórias bíblicas -, orientações didáticas gerais e específicas para as diferentes áreas do conhecimento - metodologias de ensino -, informações sobre legislação educacional e orientações administrativas para as congregações luteranas e escolas paroquiais. Destaca-se que a edição da revista aconteceu com base em princípios morais e educacionais idealizados pela IELB.

A partir da edição de julho/agosto de 1954, a revista passou a ser somente teológica, inclusive com mudança do redator, conforme fragmento apresentado na Figura 2:

Figura 2 - Fragmento com identificação da $1^{\text {a }}$ edição teológica da revista Igreja Luterana

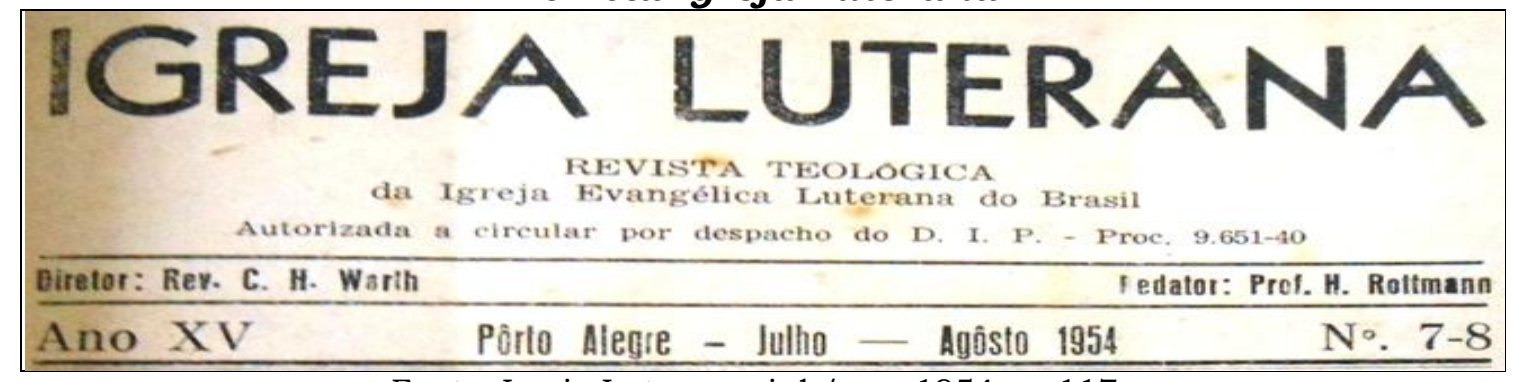

Fonte: Igreja Luterana, jul./ago. 1954, p. 117.

Atualmente, Igreja Luterana é uma revista semestral de Teologia da IELB, publicada nos meses de junho e novembro pela Faculdade de Teologia do Seminário Concórdia de São Leopoldo/RS.

\section{A MATEMÁTICA NA REVISTA TÉCNICA IGREJA LUTERANA}

$\mathrm{Na}$ análise das 95 edições da revista técnica Igreja Luterana foram localizados três artigos envolvendo Matemática. Na Figura 3 se apresenta um excerto sobre o ensino da divisão por uma fração:

\section{Figura 3 - 0 ensino da divisão por uma fração}




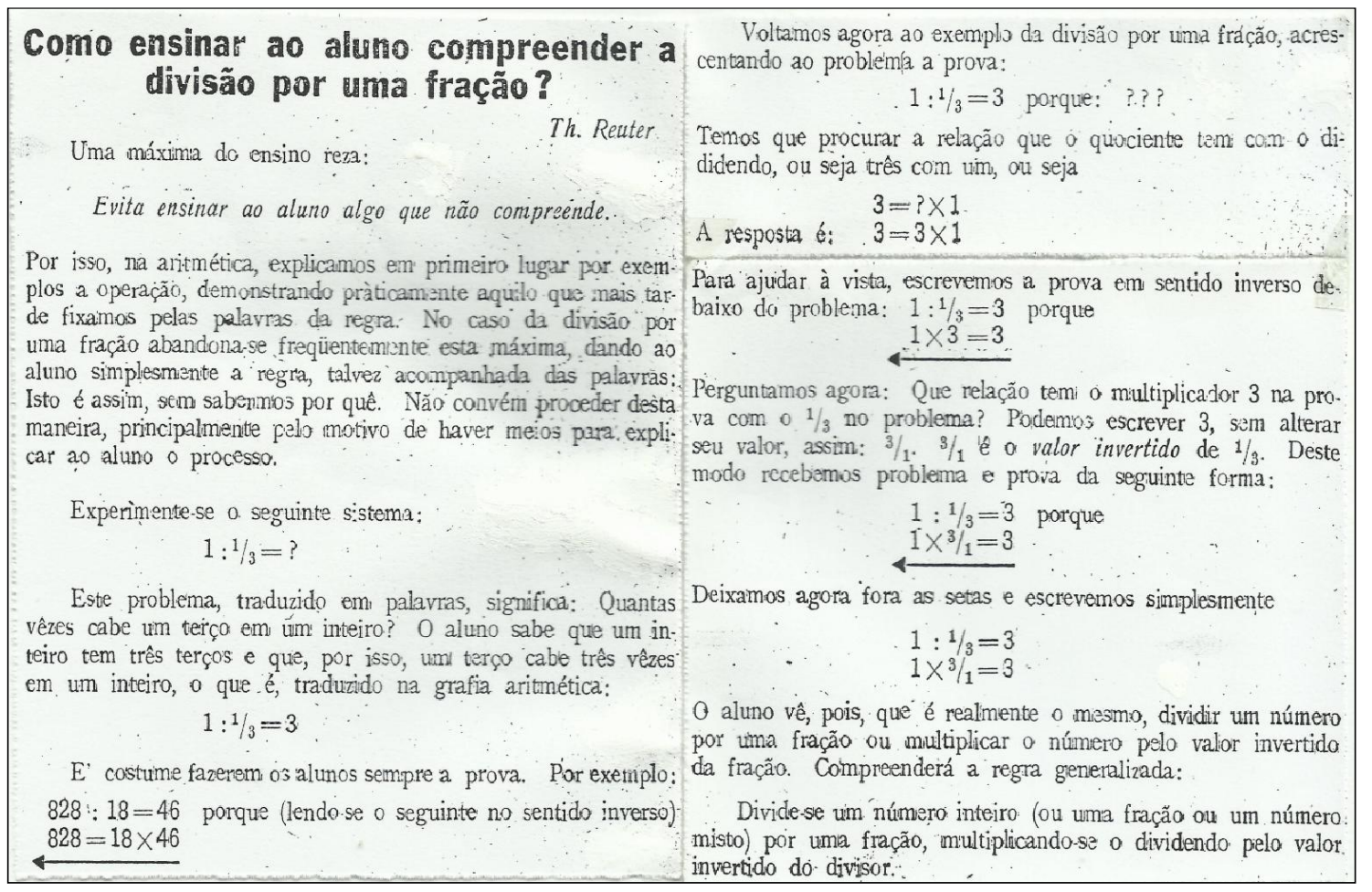

Fonte: Igreja Luterana, maio/jun. 1949, p. 139-140.

O artigo apresentado na Figura 3 mostra como o professor pode ensinar a divisão por uma fração, partindo do exemplo $1 \div \frac{1}{3}$, fazendo a explicação do processo de divisão por uma fração de forma articulada com a ideia de medida da divisão (quantos vezes cabe) e as operações de multiplicação e divisão com números naturais. O excerto é concluído com a regra geral para divisão de um número inteiro (ou uma fração ou ainda um número misto) por uma fração. Nota-se que, inicialmente, o autor faz uma reflexão sobre o ensino da divisão por uma fração, apontando que o mesmo costuma ser feito apenas com a apresentação da regra prática, sem uma explicação sobre o porquê das operações que são realizadas. Essa reflexão pode ser estendida para o ensino de Matemática de uma forma geral, pois outros conteúdos também são desenvolvidos somente pela informação da regra ou procedimento de resolução, sem uma construção do conhecimento matemático. 
No Quadro 2, descreve-se o outro artigo sobre divisão de frações, localizado na revista técnica Igreja Luterana:

\section{Quadro 2 - Mais uma vez: a divisão por uma fração}

Tendo nós procurado apresentar aos professores um modo de explicar aos alunos a operação da divisão por uma fração, encontramos em um volume de "Ev.- Luth. Schulblatt" (Vol. 19 - 1864, p. 66) um método tão singelo, que não nos podemos furtar a transcrevê-lo:

$$
\frac{3}{4} \div \frac{4}{5}=\text { ? }
$$

Procuramos o denominador comum, que é 20.

$$
\begin{aligned}
& \frac{1}{4}=\frac{5}{20}, \frac{3}{4}=\frac{3 \times 5}{20} \\
& \frac{1}{5}=\frac{4}{20}, \frac{4}{5}=\frac{4 \times 4}{20} \\
& \text { Por isso é } \frac{3}{4} \div \frac{4}{5}=\frac{3 \times 5}{20} \div \frac{4 \times 4}{20}
\end{aligned}
$$

Frações que tem o mesmo denominador, dividem-se como se fossem números inteiros, isto é, omitindo-se o denominador comum.

$$
\frac{3 \times 5}{20} \div \frac{4 \times 4}{20} \text { é, pois, igual a } 3 \times 5 \div 4 \times 4
$$

Recordando-nos de que o traço de fração é o mesmo que o sinal : (dividido por), escrevemos em lugar de 3 × $5 \div 4$ x 4 o seguinte:

$$
\begin{aligned}
& \frac{3 \times 5}{4 \times 4} \\
& \frac{3}{4} \div \frac{4}{5} \text { é pois igual a } \frac{3}{4} \times \frac{5}{4}
\end{aligned}
$$

$$
\text { Fonte: Igreja Luterana, jul./ago. 1949, p. 172-173. }
$$

No fragmento, descrito no Quadro 2, a revista técnica Igreja Luterana reforça o algoritmo e o procedimento de cálculo para a divisão de fração por uma fração, partindo do exemplo $\frac{3}{4} \div \frac{4}{5}$. Chama atenção que, o resultado da divisão, $\frac{15}{16}$, não é apresentado no exemplo observado nessa revista. Com artigos como esses, a revista técnica Igreja Luterana cumpria seu papel de dar suporte aos professores das escolas paroquiais luteranas, para que os 
mesmos pudessem atuar nos processos de ensino e de aprendizagem de seus alunos.

Um artigo da revista Igreja Luterana, intitulado Virtudes de escolares, assinado por Th. Reuter, publicado em três partes nas edições de 1949 da revista técnica, defende que as virtudes de escolares que são absolutamente necessárias para um ensino proficuo são: silêncio, atenção, aplicação, ordem, comportamento e obediência. O silêncio é considerado como uma das mais dificeis tarefas do professor. Para que os alunos guardem silêncio, sugere-se aos professores que "sejam calmos, lecionem de modo interessante, só permitam que os alunos externem sua opinião ao apontarem o dedo, façam os alunos sentirem que sempre estão sendo observados e variem a forma de verificar os temas de casa para evitar conversas desnecessárias”. (IGREJA LUTERANA, jan./fev. 1949, p. 40).

De acordo com o artigo, a atenção é uma virtude que não se consegue pela força. Não se pode obrigar uma alma a receber uma coisa, se não quer aprender, fecha-se contra o docente e a matéria. Esta virtude exige despertar bem a vontade e o interesse para o estudo. Para que o aluno tome parte na aula, recomenda-se ao professor paroquial:

a) Prepara-te para a aula. Meditou bem sobre o "O quê?" e o "Como?"

b) Leciona intuitivamente. Os termos concretos, ilustra-os por quadros, modelos ou desenhos, os termos abstratos por histórias, anedotas.

c) Leciona dum modo vivo. Faze os alunos perceber que gostas de dar aulas. Fala alegre e animadamente. Cultiva uma voz agradável e modulada.

d) Norteia o modo de apresentar a matéria por meio dos alunos medianos.

e) Dedica a cada matéria o tempo suficiente para conseguir a compreensão de quase todos. Aconselha aos que têm dificuldades em certa matéria a procurarem ensino fora do horário.

f) Pergunta a todos, pois tens obrigação para com todos.

g) Observa os que estão distraídos e pergunta-os frequentemente para obrigá-los a concentrar-se.

h) Exige sempre respostas bem audiveis para que os outros alunos permaneçam atenciosos.

i) Varia no modo de lecionar. Não fales sempre só tu, nem perguntes ininterruptamente. (IGREJA LUTERANA, jan./fev. 1949, p. 41). 
Com relação à virtude da aplicação, as orientações da revista são dadas a partir de perguntas dirigidas a um professor-modelo:

1. Que exemplo dás aos alunos no que diz respeito à aplicação? Sei que a fidelidade e diligência, manifestadas diariamente, estimulam os alunos a imitarem-nas. Não adianta exortar neste sentido sem dar um bom exemplo.

2. Como lhes encareces o trabalho?

a) Mostro-lhes a utilidade e necessidade do trabalho, a variedade de matérias que deveriam dominar para o seu bem nesta vida e naquela.

b) Torno-lhes claro que o trabalho é o bom uso do tempo que Deus lhes dá.

c) Apresento-lhes o trabalho como bela virtude, agradável a Deus e ponho diante dos seus olhos a recompensa: crescimento dos conhecimentos e das capacidades mentais e proteção contra muitas tentações.

d) Levo-os a considerarem os seus estudos como cumprimento exigido por Deus de seu estado particular de alunos.

3. Como despertas nos alunos vontade e alegria para o estudo?

a) O mais necessário é o de capacitá-los para executarem as suas lições sem auxílio de colegas ou parentes.

b) Mostro-lhes como se executam as lições para se pouparem tempo e energias.

c) Examino todas as suas lições bem como a matéria decorada, levando-os desta maneira a verem que sempre levo em consideração a sua diligência.

d) Louvando de vez em vez uma lição muito bem feita, dou-lhes a entender que me alegro com o seu progresso, não desconsiderando nem o progresso exíguo dos menos talentosos.

e) Não incito à ambição. Prefiro mostrar ao aluno negligente ou preguiçoso o modelo de seu colega diligente, sem que este, porém, ouça as minhas palavras.

4. Como procuras remediar a negligência ou preguiça?

a) Falo da má consciência com que se carrega o aluno não aplicado, e levo-o a considerar a negligência e preguiça pecados que provocam a ira de Deus e com que dão a Satanás ocasião de levá-los a outros pecados.

b) Castigo os alunos preguiçosos, mandando-os fazer as lições omitidas durante o recreio ou talvez depois da aula. (IGREJA LUTERANA, mar./abr. 1949, p. 90-91).

Ainda de acordo com o artigo, a virtude da ordem é tão necessária para cada homem que se deve insistir incansavelmente em que cada aluno se conforme com ela. Então, aconselha-se o professor paroquial da seguinte forma:

a) Se tu mesmo exemplo de ordem e disciplina.

b) Exige ordem no que diz respeito ao tempo. Os alunos têm de chegar pontualmente à escola e executar pontualmente as suas lições. Observa estritamente o horário e requer aos alunos inteirarem-se dele. 
c) Zela pela ordem no que diz respeito ao ambiente. Cada aluno tem o seu próprio lugar, não deve trocá-lo por outro ou abandoná-lo sem licença. Vigia pela limpeza do ambiente e acostuma os alunos a sentirem-se cada um responsável por ela. Interessa-te também pela ordem na pasta dos alunos e pela boa conservação dos livros.

d) Explica bem que a falta de ordem é justa razão do desprezo da parte de outros e que ela retém o aluno no progresso desejado. Lança, por isso, mão de castigos adequados, se um aluno não se quer conformar com a disciplina. (IGREJA LUTERANA, mar./abr. 1949, p. 91).

A virtude do comportamento de escolares necessita mais do que qualquer outra do bom exemplo da parte do professor paroquial. Mirando o bom comportamento dos alunos, sugere-se ao professor paroquial:

a) Não permitas que um aluno tenha as mãos ou o rosto sujo. Em casos de repetição no tocante ao mesmo aluno, manda-o com um bilhete para casa.

b) Educa os alunos a cuidarem de sua roupa (não te esqueças da tua própria roupa).

c) Olha que os alunos conservem sempre um porte de seu corpo que manifesta atenção e interesse.

d) Também no recreio faze os alunos guiarem-se pelo bom comportamento.

e) Inspeciona regularmente as privadas.

f) O comportamento se evidencia especialmente pelo modo de os alunos tratarem o professor. Não permitas intimidade ligeira, se bem que procures criar amizade para com cada aluno. Cumprimenta os teus alunos fora da aula. Os alunos que não o fazem, aprendem-no pelo bom exemplo. Agradece ao aluno que te fez um favor, e educa-os a mostrarem a ti e aos colegas gratidão, tendo recebido um favor.

g) Proíbe qualquer deslize por nomes feios entre os alunos.

h) Ensina os alunos a repreenderem amigavelmente eles mesmos um colega que se comportou mal.

i) Dois alunos que têm mutuamente uma aversão dificilmente corrigivel, não deveriam estar sentados um ao lado do outro para não levá-los em tentação. (IGREJA LUTERANA, mar./abr. 1949, p. 91).

A obediência é algo que deve ser aprendido. A criança deve se dominar. A comodidade e inclinações particulares devem ceder à vontade do mestre. De acordo com o artigo, todas as ordens têm também a finalidade de o súdito aprender a obediência, pois o exercício na obediência afoga o velho homem:

Obediência pressupõe uma ordem. Nenhuma ordem dá a força para o cumprimento (nem os Mandamentos de Deus), mas sucede que há ordens de dificultam ou até anulam a obediência. O mestre deve estar convicto da possibilidade de cumprimento do conteúdo. A 
respeito de sua forma, a ordem seja breve, precisa, para facilitar a compreensão e para não dar ocasião de procurar-se uma escusa nas muitas palavras. É supérfluo explicar sempre os motivos para a ordem para não causar dúvidas quanto à necessidade do cumprimento. Tão certamente como a criança deve obedecer em tudo que não contraria a Palavra de Deus, tão prejudiciais tornam-se ordens que se contradizem a si mesmas. (IGREJA LUTERANA, maio/jun. 1949, p. 137).

O artigo da revista complementa que é vantajoso dirigir a atenção dos alunos para os seguintes fatos:

a) Guardar os Mandamentos de Deus é o ambiente de vida do novo homem.

b) Deus quer que obedeçam aos pais e professores e os honrem.

c) Obedecendo a homens, que Deus pôs sobre eles, servirão ao Senhor.

d) Obediência não constitui vergonha, mas é o mais belo adorno do cristão.

e) Um filho de Deus deve gostar de fazer a vontade de Deus. (IGREJA LUTERANA, maio/jun. 1949, p. 137-138).

Com esses artigos de cunho pedagógico, os editores da revista técnica Igreja Luterana procuravam dar suporte aos professores das escolas paroquiais luteranas de acordo com os princípios morais e educacionais idealizados pela IELB.

Na revista técnica Igreja Luterana também se localizou um relatório, de 1951, sobre o programa do $1^{\circ}$ ano primário do Colégio Concórdia de Porto Alegre $^{14}$. A professora regente, Ilse Evers, escreve que nos primeiros meses do ano letivo as crianças não têm horário propriamente dito. Só a professora faz uso do mesmo para sua própria orientação. "As primeiras aulas são intercaladas de jogos, palestras e pequenas histórias e de tudo que desperta o interesse das crianças e que lhe torna agradável o ambiente de aula. A partir de maio trabalhamos dentro do horário fixado" (IGREJA LUTERANA, out./dez. 1951, p. 219). Com relação ao ensino da Aritmética, na Figura 4 se apresenta o programa descrito pela professora Ilse Evers, para o $1^{\circ}$ ano primário do Colégio Concórdia de Porto Alegre:

${ }^{14}$ Foi fundado em 1902, como escola paroquial luterana. 


\section{Figura 4 - 0 ensino de aritmética no $1^{\circ}$ ano primário do Colégio Concórdia}

\begin{tabular}{|c|c|}
\hline 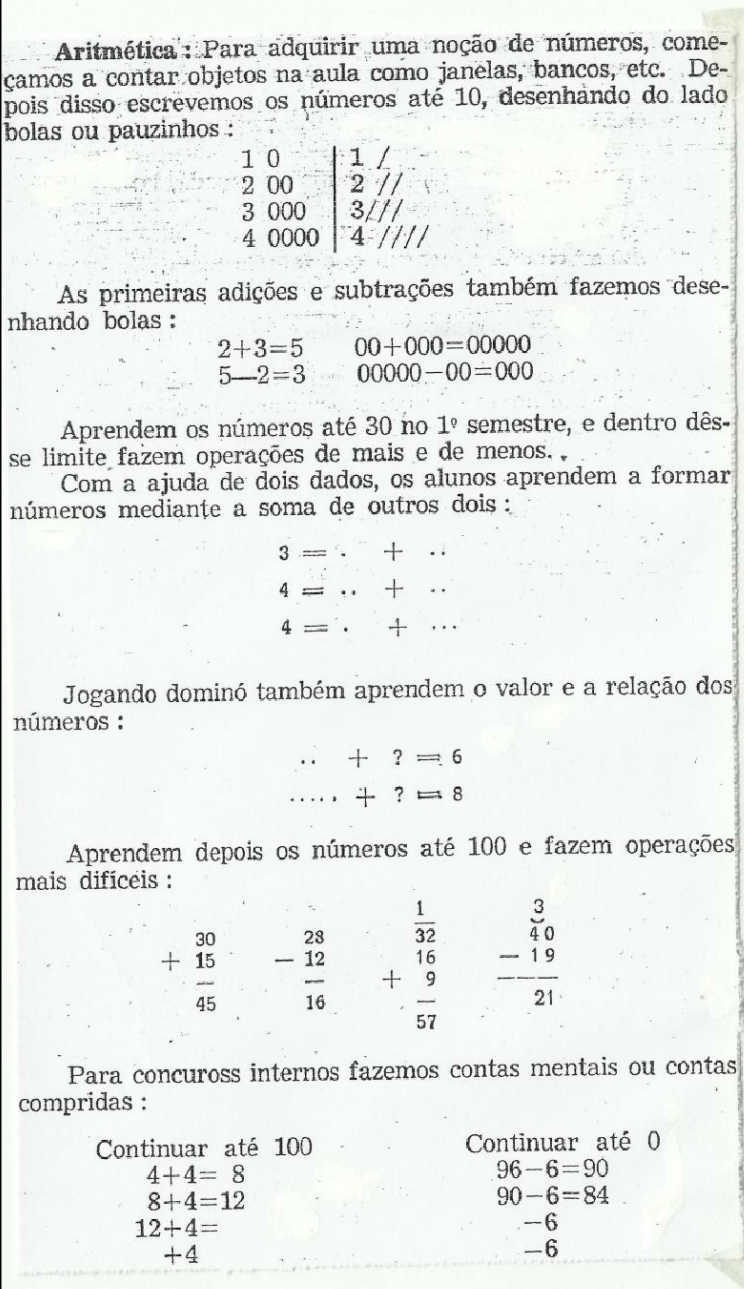 & 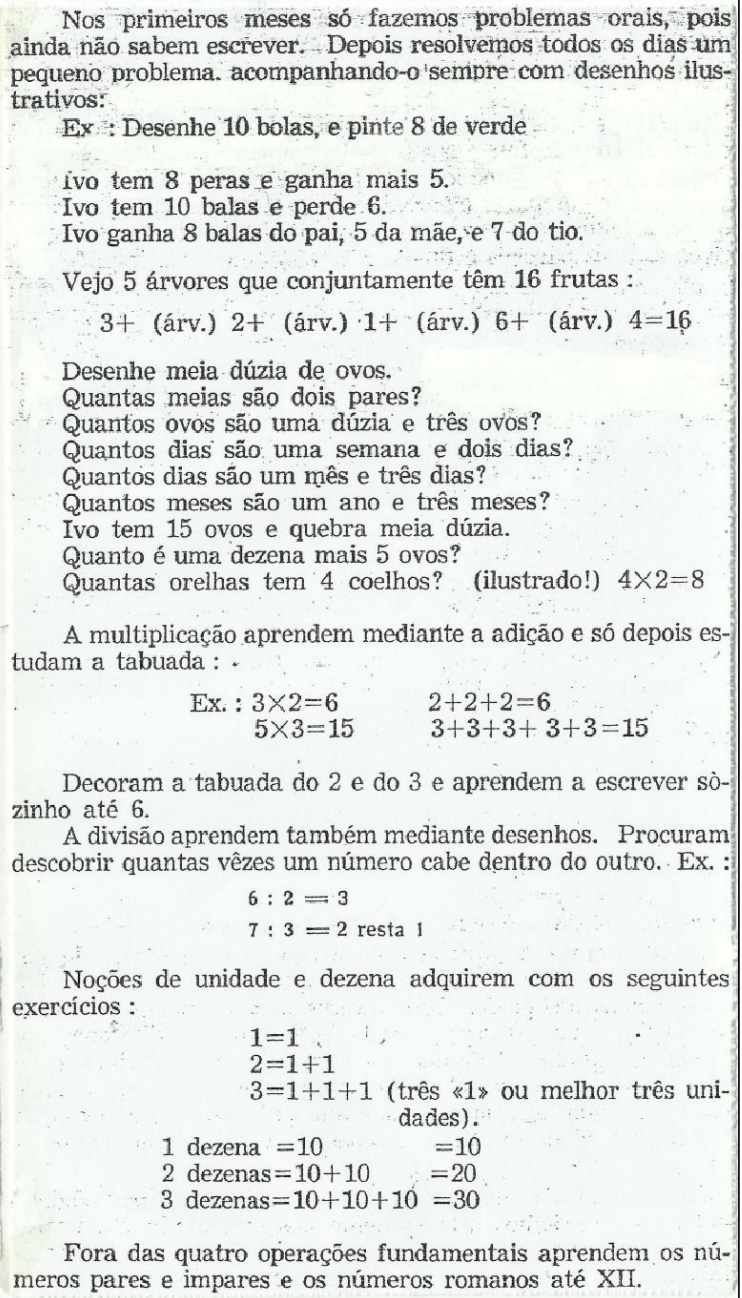 \\
\hline
\end{tabular}

Fonte: Igreja Luterana, out./dez. 1951, p. 222-223.

O fragmento apresentado na Figura 4 evidencia o ensino das operações de adição e subtração pelo método intuitivo. Esse método surgiu na Alemanha no final do século XVIII e foi divulgado pelos discípulos de Pestalozzi no decorrer do século XIX, na Europa e nos Estados Unidos. No 
Brasil, fez parte das propostas de reformulação da instrução pública no final do Império, sendo Rui Barbosa responsável por sistematizar os princípios do método intuitivo em seus pareceres e por traduzir o manual, Lições de Coisas, de Calkins. Para Pestalozzi, a formação do aluno se dá conforme sua personalidade, suas aptidões e iniciativas. Por isso, defende uma educação que cultive harmonicamente as diferentes faculdades humanas (o cérebro, o coração e as mãos) para transformação da sociedade. No método intuitivo, a escola deveria ensinar coisas vinculadas à vida, utilizar os objetos como suporte didático e os sentidos para produção de ideias, iniciando do concreto e ascendendo à abstração (COSTA, 2014).

O excerto mostrado na Figura 4 faz referência ao uso de materiais concretos, como os dominós, e de ilustrações para construção dos significados de somar e diminuir e resolver problemas. Apresentam-se algoritmos de cálculo para as operações de adição e subtração, destacandose as contas compridas envolvendo essas operações. Enquanto os alunos de uma série se ocupavam com as contas compridas ou contas tripas, o professor atendia outra série, pois, nessa época, a maioria das escolas paroquiais eram multisseriadas. Exploram-se o cálculo mental e escrito, com algoritmos de cálculo para as quatro operações, chamando atenção, ainda, a ideia de multiplicação como uma soma de parcelas iguais e a ideia de divisão como uma medida (TOLEDO; TOLEDO, 1997). A construção do sistema decimal envolve noções de unidade e dezena, pois o primeiro ano se limita ao estudo da numeração até 100. Registra-se ainda a prática da tabuada até 6 , o estudo dos números pares e ímpares e dos números romanos até XII.

No ensino da Matemática, conforme Kreutz (1994), a prioridade eram as operações básicas que pudessem ser feitas mentalmente, nas circunstâncias concretas da vida agrária, seja na forma, como no conteúdo. Por isso, dava-se ênfase aos Kopfrechnungen (cálculos feitos mentalmente), já que na vida agrícola a pessoa teria que calcular, com frequência, sem ter o papel e lápis à mão. O próprio título de um dos manuais usados nas escolas de imigrantes alemães no RS, o Praktische Rechenschule (o ensino prático da matemática), de Otto Büchler, reflete este entendimento. 
A partir dos artigos localizados na revista técnica Igreja Luterana e voltados para o ensino de Matemática nas escolas paroquiais luteranas, concorda-se com Weiduschadt (2007), com relação à valorização da Matemática:

\section{Considerações finais}

Pela necessidade de trabalho e para ser usada na vida cotidiana a matemática era muito valorizada. O ensino da matemática era difundido, pois, a criança necessitava ter dominio desse conhecimento para poder usar no dia a dia. Aprendiam os conceitos elementares e práticos da matemática. (WEIDUSCHADT, 2007, p. 195).

Como as escolas paroquiais luteranas gaúchas do século XX estavam inseridas num projeto missionário e comunitário que buscava ensinar a língua materna, a Matemática, valores culturais, sociais e, principalmente, religiosos, a IELB se preocupou em produzir materiais pedagógicos para suas escolas. Através da Casa Publicadora Concórdia, de Porto Alegre, a IELB editou e publicou livros didáticos e periódicos, como a revista técnica Igreja Luterana, de acordo com seus princípios morais e educacionais. Além de educarem e doutrinarem pela palavra de Deus, os periódicos editados pela Igreja Luterana se direcionavam para os pastores, professores paroquiais e crianças luteranas, trazendo artigos com orientações didáticas e informações sobre conteúdos formais.

Fundamentando-se no referencial teórico-metodológico da pesquisa histórica e do conceito de cultura escolar, investigaram-se as 95 edições da revista técnica Igreja Luterana, editada no período de janeiro de 1940 a abril/junho de 1954, quando passou a ser somente teológica. A revista possuía caráter técnico (teológico/pedagógico) para pastores e professores luteranos. Era desejo dos editores da revista que os professores das escolas paroquiais luteranas estivessem aptos para darem aos alunos uma instrução e educação verdadeiramente cristãs, por isso, a abordagem de temáticas teológicas e pedagógicas. Nas edições técnicas da revista Igreja Luterana se encontram textos religiosos, geralmente, histórias bíblicas, orientações didáticas gerais e específicas para as diferentes áreas do conhecimento, 
informações sobre legislação educacional e orientações administrativas para as congregações luteranas e escolas paroquiais.

Com relação à Matemática presente na revista técnica Igreja Luterana, constatou-se que os editores propunham artigos voltados ao desenvolvimento de habilidades para o cálculo escrito e mental, com foco nas primeiras construções numéricas pelo método de ensino intuitivo e na operação de divisão com frações. Destaca-se a preocupação dos autores dos artigos com a compreensão dos conhecimentos matemáticos e não apenas com o conhecimento de regras ou procedimentos para resolução de cálculos.

\section{Referências}

CERTEAU, Michel de. A escrita da História. Tradução Maria de Lourdes Menezes. Rio de Janeiro: Forense Universitária, 1982.

CHERVEL, André. História das disciplinas escolares - reflexões sobre um campo de pesquisa. Teoria \& Educação, Porto Alegre, RS, n. 2, p. 177-229, 1990.

COSTA, David Antonio da. As concepções e contribuições de Pestalozzi, Grube, Parker e Dewey para o ensino da aritmética no nivel elementar: o conceito de número. História da Educação, Porto Alegre, RS, v. 18, n. 42, p. 37-59, jan./abr. 2014.

IGREJA LUTERANA. Porto Alegre: Casa Publicadora Concórdia, 1940-1954.

JULIA, Dominique. A cultura escolar como objeto histórico. Revista Brasileira de História da Educação, Campinas, SP, n. 1, p. 9-43, jan./jun. 2001.

KREUTZ, Lúcio. Material didático e currículo na escola teuto-brasileira. São Leopoldo: Ed. UNISINOS, 1994.

KUHN, Malcus Cassiano; BAYER, Arno. A matemática nas escolas paroquiais luteranas gaúchas do século XX. Canoas: Ed. ULBRA, 2017a.

KUHN, Malcus Cassiano; BAYER, Arno. O contexto histórico das escolas paroquiais luteranas gaúchas do século XX. Canoas: Ed. ULBRA, 2017b.

LEMKE, Marli Dockhorn. Os princípios da educação cristã luterana e a gestão de escolas confessionárias no contexto das ideias pedagógicas no sul do Brasil (1824 - 1997). Canoas: Ed. ULBRA, 2001. 
PROST, Antoine. Doze lições sobre a História. Belo Horizonte: Autêntica, 2008.

SCHUBRING, Gert. Relações Culturais entre Alemanha e Brasil:

"Imperialismo Cultural" versus "Nacionalização". Zetetiké - Cempem, Campinas, SP, v. 11, n. 20, p. 9-49, jul./dez. 2003.

TOLEDO, Marília; TOLEDO, Mauro. Didática de matemática: como dois e dois: a construção da matemática. São Paulo, FTD, 1997.

UNSERE SCHULE. Porto Alegre: Casa Publicadora Concórdia, ago. 1933.

UNSERE SCHULE. Porto Alegre: Casa Publicadora Concórdia, mar./abr. 1934.

VALENTE, Wagner Rodrigues. História da Educação Matemática: interrogações metodológicas. REVEMAT - Revista Eletrônica de Educação Matemática, Florianópolis, SC, v. 2.2, p. 28-49, 2007.

WEIDUSCHADT, Patrícia. O Sínodo de Missouri e a educação pomerana em Pelotas e São Lourenço do Sul nas primeiras décadas do século XX:

identidade e cultura escolar. 2007. 255 f. Dissertação (Mestrado) - Programa de Pós-Graduação em Educação, Universidade Federal de Pelotas, Pelotas/RS, 2007. 